Journal of Social Sciences (COES\&RJ-JSS)

ISSN (E): 2305-9249 ISSN (P): 2305-9494

Publisher: Centre of Excellence for Scientific \& Research Journalism, COES\&RJ LLC

Online Publication Date: $1^{\text {st }}$ January 2019

Online Issue: Volume 8, Number 1, January 2019

https://doi.org/10.25255/jss.2019.8.1.157.168

\title{
Translation of Political Neologisms Coined by Politicians; Issues and Strategies
}

\section{Mohammad Faleh Hanaqtah}

University of Jordan

Major: Translation \& Interpretation

Jordan- Aqaba

Email:m-hanaqtah@hotmail.com

\begin{abstract}
:
Most of the neologisms which are coined by politicians are strange to the Arabic language linguistically and culturally. Niska $(1998$, p. 89) states that "neologisms are tokens of a creative process "a novel relational product growing out of the uniqueness of the individual on the one hand, and the materials, events, people, or circumstances of his life on the other". Translating neologisms accurately and finding the right equivalents is a problematic issue. This study endeavors to investigate the translation problems of political neologisms and the strategies used to translate these neologisms. In order to achieve the objectives of the study the methodology which is used is qualitative method. As a theoretical frame work for the study Peter Newmark's dual theory of semantic and communicative methods of translation in addition to his translation procedures model for the translation of different types of neologisms will be utilized. The results show that political neologisms are culturally loaded and difficult to translate without having good background knowledge of these neologisms. Translators should have a good command of both source and target languages and should be culturally and linguistically competent in order to be able to translate neologisms. It also shows that the most frequently used strategies were functional equivalent, word for word, modulation, paraphrasing, and compensation. The least frequently used strategies were couplets, componential analysis, omissions, additions, reduction, expansion and transference.
\end{abstract}

\section{Keywords:}

Neologisms, semantic and communicative translation.

\section{Citation:}

Hanaqtah, Mohammad Faleh (2019); Translation of Political Neologisms Coined by Politicians; Issues and Strategies; Journal of Social Sciences (COES\&RJ-JSS), Vol.8, No.1, pp:157-168; https://doi.org/10.25255/jss.2019.8.1.157.168. 


\section{Introduction}

Translation has become of great importance in recent decades due to the fact that it allows the people to overcome cultural and linguistic barriers (Alnajrani et al., 2018; Bajnaid et al., 2018). Newmark who described the conversion of a text from one language to another as a science and an art at the same time defines translation as "a craft consisting in the attempt to replace a written message and/or statement in one language by the same message and/or statement in another language" Newmark (1981, p.7). Another scholar Bell (1991, p.15) defines it as "the transformation of a text originally in one language into an equivalent text in a different language retaining, as far as possible, the content of the message and the formal features and functional roles of the original text" It is "the skill of understanding the source text and rendering it in the target language by using the register, the background knowledge, and other language resources according to the intended purpose" Kelly (2005, p. 26). The translation of neologisms in the political field in particular is a difficult task that translators face. Newmark (1988, p.141) states that "The trouble with the translation of political language is that it is an abstraction of an abstraction". He adds "Neologisms are perhaps the nonliterary and the professional translator's biggest problem. New objects and processes are continually created in technology. New ideas and variations on feelings come from the media" Newmark (1988, p.140).

The difficulties come from the fact that there is often a lack of ready equivalents for these neologisms in the target language and that these neologisms are culturally loaded or not included in dictionaries. According to Sheidlower (1995, p.53) "dictionaries only record words that meet their criteria for inclusion, which may be based on frequency, range of use, time span of use, and judgments about a word's cruciality that is, the need for it to be in the language". Politicians are prone to coin neologisms to disguise the truth, hide scandals and guide public thoughts when discussing social issues or events. Behind these neologisms there is often a hidden message and they sometimes suggest the opposite of what is really meant. There is always a purpose behind using a particular term which makes it difficult to be understood. Due to the cultural and linguistic differences between Arabic and English and due to the characteristic of newness translators, in many cases face some difficulties when they try to translate these neologisms. Mattielo says that "most difficulties arise because this action crosslinguistically requires a lot of effort to find similar modes of expression and cross culturally demand for parallel social sets" Mattielo (2007, p.39). The problems also include finding the right equivalents in Arabic for these neologisms. The lack of information about the meaning of these neologisms in dictionaries even the newest and most updated ones especially Arabic dictionaries. The fact that some of these neologisms are idiomatic expressions which make their translation very difficult because these terms have a particular meaning different from the meaning of each word understood on its own. Nolan (2005, p. 67) believes that "The most common pitfall to be avoided is not recognizing figurative or idiomatic language and translating it literally". For of all the above-mentioned problems translators in most cases fail to convey the same impact as the ST which leads to inaccurate and inadequate translation. 
Hence the purpose of this research is to examine problems in translating English neologisms coined by politicians and to investigate the translation strategies or methods which are adopted by professional translators in rendering these neologisms from English into Arabic. Qualitative method will be used to analyze the data in order achieve the research objectives. Newmark's translation methods namely communicative and semantic will be used in addition to his translation procedures model as the basis for the analysis of the translation of neologisms.

\section{Political Language}

Politics as a general and universal aspect of human activity pervades every aspect of human thought. According to Oxford Dictionary (2015) "Political Jargon refers to the words and phrases used by politicians, lobbyists, the media, and other people to talk about political issues in a quicker, coded way. Political jargon is the shared language of catch phrases spoken by those in politics". Political texts cover different genres such as: political speeches, press conferences with politicians, multilateral treaties, and commentaries in newspapers, editorials, and politician's memoir. Politicians use their political language skills as a powerful tool in gaining public support and political advantages. They depend on the slogans and propaganda, rather than telling the truth to the people to achieve their goals because if they did that no one will vote for them. According to Crystal (1995, p.378) "The language of politicians, especially when they are speaking in public, is an interesting mixture of old and new". He adds"it displays much of the ritual phraseology and consciousness of precedent which we associate with religion or law; and it makes use of many of the rhetorical and dramatic techniques which we associate with advertising or the media. It is a variety which is much abused".

Newmark (1988, p.153) has a similar point of view "Political language is particularly susceptible to a quick 'accept' and 'reject' and every word as well as every person gets ten minutes of fame". The language they use has many acceptable and unacceptable lies and empty promises. Their main objective is to persuade people of their ideas rather than guiding them. They use fancy and wonderful language which in most cases means nothing or mean the opposite of what really meant.

From all this it can be noticed that it is not easy for a translator to render English political terms into Arabic without taking into consideration the emotive function of language and its effect on changing the emotive state of the recipients. Translators should be fully aware of the fact that political terms may be highly emotive in one language, but they are not so in the target language. "The media constantly plays word game, changing our perception of ideas through the words they use to describe them" Schäffner (1997, p. 119). For instance, are suicide bombers militants 'مسلحين' one country's terrorists are another country's freedom fighters مدافعين عن الحرية.

\section{Neologisms}

As stated before politicians have the tendency to create new terms. They do that for different reasons like hiding, shading or disguising the truth, to calm fears and obscuring the meaning rather than enhancing it. According to the Oxford English Dictionary (2016) 
a neologism is "a newly coined word that may be in the process of entering common use, but has not yet been accepted into mainstream language".

The term entered into English (according to the Oxford English Dictionary-or O.E.D.) toward the end of the 18th century. Harmann \& James (1998, p.43) define neologism as "a word or phrase which has entered the language relatively recently, often commented on and collected in specialized dictionaries". According to Fischer $(1998$, p. 45) neologism is "a word which has lost its status of a nonce-formation but is still one which is considered new by the majority of members of a speech community". Leibold (1989, p.110) describes neologisms as the "combination or modification of existing words, or the addition of modifying prefixes and suffixes to words to 'condense or simplify the message and accelerate delivery".

Newmark also defines it as "newly coined lexical units or existing lexical units that acquire a new sense" Newmark (1988, p.140). After being coined the new terms are used in order to see their suitability for the language; some are accepted others are rejected and disappear from common usage especially those dealing with sensitive matters such as religions and racism. Newmark proposed twelve types of neologisms which he divides into two groups: The first group comprises lexical items with new senses in the form of words and collocations. The second group comprises new forms that include new coinages, derived words (including blend, abbreviations, collocations, eponyms, phrasal words, transferred words (new and old referents), acronyms (new and old referents), pseudo- neologism, and internationalism Newmark (1988, p.140).

Neologism passes through three stages "creation, trial and establishment" Parianou \& Kelandrias (2002, p.756). Indeed, new words are not always "new" As Metcalf (2002, p.5) suggests, "Successful new words often turn out to be older than we think". They are coined to apply to new concepts or to reduce older terms in a different form. They emerge most frequently in situations where there is fast propagation of information and in rapidly-changing cultures. They come from a wide range of sources, such as political and economic reform, improved living standards, more diverse cultural life, new and high technology, evolved education system, more flexible job market, and emerging social challenges. Neologisms often become popular through word of mouth or by way of mass media and the internet which makes them spread like wildfire. When it appears in glossaries and dictionaries it is then an indication that it has gained the approval of lexicographers.

Rey distinguishes three types of neologisms and also adds a special category as a result of the tendency of modernization appeared under the name of luxury neologisms "Formal, Semantic and Pragmatic" Rey (1975, p.54).

Silvia (2001, p.35) differentiates between two types of neologisms 'morphological neologisms and semantic neologisms. The morphological neologisms are created through derivation compounding, blending, acronyms, and borrowing. The semantic neologisms, result from the followings: First the expansion which means extension of the meaning of a term by giving it a new meaning. Second from the metaphor which means the process 
whereby a word or expression is used to refer to something other than what it was originally applied to, or what it 'literally' means. Third the conversion of grammatical category and the adoption from another subject field.

Cabré mentions a number of ways to determine if a unit is neologism or not. She states that "a unit is a neologism if it has arisen recently, if it is not in dictionaries, if it exhibits signs of formal instability (e.g. morphological, graphic, phonetic) or semantic instability and if speakers perceive it as a new unit". She also states that neologisms can be classified into referential or expressive based on their function "referential neologisms develop because they are required, i.e. there is a gap in a specific special field that must be filled; expressive neologisms develop simply to introduce new forms of expression into the discourse" (Cabré 1999:206). She also points out that neologisms differ from one another in several features: 1 . in their creation 2.in their primary function 3.in their relationship with co-occurring synonyms 4 .in the resources favored for creating the word 5 .in their continuance in the language 6 .in the way they coexist in the system 7 .in the way they relate to other systems.

In this case a question should be raised what should translators do when they come up against new terms that cannot be translated? Some may suggest that the translator should describe these terms so that they make sense in the target language. But some may say that some terms pose more difficulty than others due to cultural differences. Beaugrande (2003, p.78) states "The priority of the translator is to invest a welldeveloped bilingual sensitivity and bicultural sensitivity in weighing the complex or competing factors of the translation process, such as the multiplex relations between word-meanings and text-meanings in light of cultural difference" .

On the other hand, Newmark (1988, p. 143) suggests that "any kind of neologism should be recreated, if it is a derived word it should be replaced by the same or equivalent morphemes, if it is also phonaesthetic, it should be given phonemes producing analogous sound effects". It is not only the translator's right to create neologisms but, in a literary text, "it is his duty to re- create any neologism he meets" (ibid.149). The researcher believes that the main task of the translator, before translating the word, is to define the function of the neologism and its motivation for being in that particular place. Translators have to pay attention to neologisms and euphemistic expressions while translating. Ignoring them will cause confusion for the target readers. Ignoring them means misunderstanding the context in which the text is produced. Translators have to find out the meaning of new neologisms mainly based on the context whether that context consists of a sentence, a paragraph, or a complete document. The researcher also agrees with what Nemark stated, translators have to create names for new scientific neologism that does not exist in the source culture. "The task of the translator in science fiction is made more complicated by the fact that, apart from mediating between cultures, he or she has to create names for things that do not exist in reality, not even in the source culture" Newmark (1991, p.44).

Different scholars such as Cabezas \& Moreno (1997,p.100) believe that translators attempting to translate neologisms should know the way words are formed in the target 
language. They should have previous knowledge of the particular domain in question, and they should have knowledge of the linguistic and social criteria that define a neologism. Delabastita $(2004$, p. 885$)$ proposes five general techniques for the translation of neologisms. (1) Directly copying the source-text neologism, with or without involving special signals (italics, inverted commas). (2) Annotation (intra textual glossing through couplet, extra textual glossing through footnotes). (3) Phonological/ graphological adaptation using an existing target-language neologism even though it has a slightly different denotational meaning. (4) Using a denotationally equivalent but nonneologistic expression in the target language. (5) Reproducing the neologistic style but in different textual positions and by means of different linguistic devices (compensation).

\section{Translation Strategies}

Translation strategies mean how the translators are going to overcome the problems they face by finding an appropriate translation solution through a suitable translation procedure. Lorscher $(1991$, p.76) defines translation strategy as "a potentially conscious procedure for the solution of the problem which an individual is faced with when translating a text segment from one language to another". Venuti (1998:240) translation strategies "involve the basic tasks of choosing the foreign text to be translated and developing a method to translate it". Hurtado (1999:36-37) suggests the following strategies: "extension, amplification, compression, discursive creation, description, generalization, particularization, reduction, paralinguistic or linguistic substitution, and variation". Ayora (251-383) distinguishes between (i) oblique translation procedures (adaptation, amplification, compensation, equivalence, explicitation, modulation, omission and transposition) and (ii) direct methods (calque, loan and literal translation).

Seguinot $(1989, p .43)$ suggests three strategies employed by the translators: (i) translating without interruption for as long as possible; (ii) correcting surface errors immediately; (iii) leaving the monitoring for qualitative or stylistic errors in the text to the revision stage. Other procedures were suggested by Vinay and Dalbernet which include adaptation, calque, equivalence, modulation, borrowing, literal translation and transposition. Lastly the18 translation procedureswhich were introduced by Newmark. A number of scholars like (Chuquet and Pallard 10, Kelly 133, Larose 18) have criticized the nature of these procedures. They believe that borrowings and calques for example, are not translation procedures. They also believe that knowing them is not useful for the translator and there is no clear boundary between them and some of these procedures for instance adaptation are beyond the limits of translation. Other scholars have a different point of view.

According to Hurtado (1999, p.p 43-44) Understanding and knowing when to apply such procedures, however, can be very helpful and methodologically useful for students. Malone supports this idea by stating that such strategies or procedures "will serve either as tools for the study of completed translation (the analytic mode), or as helpmates in the act of translation (the operative mode)". 
Translation of Political Neologisms Coined by Politicians; Issues and Strategies

Table 1. Political Neologisms and Methods of Translation

Table 1. Political Neologisms and Methods of Translation

\begin{tabular}{|c|c|c|c|c|c|c|}
\hline $\mathrm{Sr}$ & SL & TL texts & Accuracy & Economy & Naturalness & Method of translation \\
\hline 1 & $\begin{array}{c}\text { Airspace } \\
\text { deconfliction }\end{array}$ & الاسيلحة في الجو تصادم نيران & + & - & + & $\begin{array}{c}\text { Reduction and } \\
\text { expansion }\end{array}$ \\
\hline 2 & Big tent & الخيمه الكبيرة & - & + & - & Literal translation \\
\hline 3 & Bork & اغتبال الشخصبة & + & + & + & Functional equivalent \\
\hline 4 & Bully Pulpit & منابر الراي والسلطة & + & + & + & Modulation \\
\hline 5 & $\begin{array}{c}\text { Compassionate } \\
\text { conservative }\end{array}$ & المحافظ المعتدل & + & + & + & Word for word \\
\hline 6 & Infamy & الخزب شائن يبعث على العار & + & - & + & Modulation \\
\hline 7 & Decider & المقرر & + & + & + & Word for word \\
\hline 8 & Embetter & تحسين & + & + & + & Word for word \\
\hline 9 & Frazzle & إرهاق & + & + & + & Word for word \\
\hline 10 & Iffy & غير مؤكد & + & + & + & Word for word \\
\hline 11 & Instant President & الرئيس غير المنتخب & + & - & + & Functional equivalent \\
\hline 12 & Loose cannon & منهور & + & + & + & Paraphrase \\
\hline 13 & Lunatic Fringe & حركتة سياسية منطرف & + & - & + & Functional cquivalent \\
\hline 14 & $\begin{array}{c}\text { Misunderestimate } \\
\mathrm{d}\end{array}$ & استخفو ا بقدر اته & + & + & + & Functional equivalent \\
\hline 15 & Moondoggle & مضروعة للوقت والمثاف القمر & + & - & + & Functional equivalent \\
\hline 16 & New Frontier & الزواد الجدد & + & + & + & Functional equivalent \\
\hline 17 & Romnesia & العدم تذكر الشخص وذلك بقول قاله & + & - & + & Compensation \\
\hline 18 & Sputnik moment & الامة اللخة الحانمة في تاريخ & + & - & + & Compensation \\
\hline 19 & Suicider & إنتحاري & + & + & + & Word for word \\
\hline 20 & $\begin{array}{l}\text { Voodoo } \\
\text { economics }\end{array}$ & لانعاشة الاقتصناد الضر ائب & + & - & + & Functional equivalent \\
\hline 21 & Wee-weed up & سببعيع يفقد اعصابه بدون & + & - & + & Functional equivalent \\
\hline 22 & Women of cover & المحجبات & + & + & + & Transference \\
\hline 23 & Blue on Blue & نير ان القوات الصديقة & + & + & + & Literal translation \\
\hline 24 & $\begin{array}{c}\text { Branches \& } \\
\text { Sequels }\end{array}$ & تعديل الخطة و القدرة على & + & - & + & Modualtion \\
\hline 25 & Butter Bar & ملازم ثاني & + & + & + & Functional equivalent \\
\hline 26 & $\begin{array}{c}\text { Collateral } \\
\text { Damage }\end{array}$ & الاضر ار الجانبية & - & + & - & Word for word \\
\hline 27 & $\begin{array}{c}\text { Catastrophic } \\
\text { success }\end{array}$ & نجاح كارثي & - & + & - & Word for word \\
\hline 28 & Dead-enders & الفذائيين & + & + & + & Cultural equivalent \\
\hline
\end{tabular}




\begin{tabular}{|c|c|c|c|c|c|c|}
\hline 29 & Embedding & بالوحدات العسكرية الملحقين & + & - & + & Descriptive equivalent \\
\hline 30 & $\begin{array}{l}\text { Sensitive site } \\
\text { exploitation }\end{array}$ & توالقتيش المواقع العسكرية عن الوثائق & + & - & + & Modulation \\
\hline 31 & Rapid Dominance & العديمنة السريعة على & + & - & + & Addition \\
\hline 32 & Fixing & تثبيت العدو & + & - & + & Addition \\
\hline 33 & Mouseholing & الجدراث & + & - & + & Functional equivalent \\
\hline 34 & Geardo & 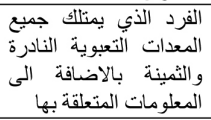 & + & - & + & Descriptive equivalent \\
\hline 35 & Granularity & معلو مات مفصلة & + & - & + & Functional equivalent \\
\hline 36 & Strike Package & الصنربيه & + & - & + & Compensation \\
\hline 37 & $\begin{array}{c}\text { Maneuverist } \\
\text { approach }\end{array}$ & التدمبرة & + & - & + & Functional equivalent \\
\hline 38 & Kinetic Strike & شن عمليات عسكرية & + & - & + & Functional equivalent \\
\hline 39 & Kill Boxes & منطقة الثقتيل & + & + & + & Componential analysis \\
\hline 40 & $\begin{array}{l}\text { Effects- Based } \\
\text { warfare }\end{array}$ & 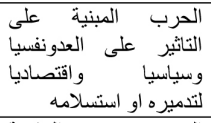 & + & - & + & Couplets \\
\hline 41 & Digital Battlefield & الكاملةوبة & + & - & + & Compensation \\
\hline 42 & E.P.W \& P.O.W & اسرى الحرب & + & + & + & Cultural equivalent \\
\hline 43 & Set-piece battle & لها بدقة المعرة المنفذه و المخطط & + & - & + & Functional equivalent \\
\hline 44 & $\begin{array}{c}\text { Vertical } \\
\text { envelopment }\end{array}$ & الإحطاطة أو الآلتفاف حوله & + & - & + & Modulation \\
\hline 45 & $\begin{array}{c}\text { Yapping like a } \\
\text { rabbit }\end{array}$ & ثرثار كالبيغاء & + & - & + & Cultural equivalent \\
\hline
\end{tabular}

\section{Analysis and Research Discussion}

Since this study limits itself with the translation of unit of neologisms and not of a specific text as a whole, the focus in conducting the content analysis was on the translational procedures, particularly, Newmark's translation procedures model. The results of the analysis serve as the basis of identifying the appropriate approach for investigating the research questions and achieve the research objectives. After analyzing the data, it was found that there are no standardized solutions, no standard translation guidance, guidelines or principle standards for the translation of political neologisms that the translators can follow, which leads to weak translation or different translation versions of the same term. Political neologisms are bound to a culture under specific conditions which lead to a semantic gap between both languages and cultures. Translators often fail to convey all the nuances and the subtleties of political neologisms due to lack of culture awareness and being unaware of the cultural implications and differences in norms and conventions between languages, in this case between Arabic and English. The difficulty of overcoming the problem of translating culture specific terms is a major problem as some of these terms may not be translatable. According to Newmark $(1988$, p.167) "a word denoting an object, an institution, or if such exists, a psychological characteristic peculiar to the source language culture is always more or less untranslatable". 
In many cases, these political neologisms do not have identical equivalents or corresponding lexical items in the target language, and even if they have, the corresponding items may not have the actual required meaning. The result of the structural differences in the features, vocabulary, and syntax of the two languages involved is a linguistic translation problem. In many cases dictionaries are of limited use, even the newest specialized dictionaries, and the most influential Arabic -English dictionaries can hardly keep up with the pace of advance and development of political neologisms and offer sound translations. Many political neologisms are so recent that they are not listed or included in dictionaries. This makes it hard for the translators to understand and master the connotation and denotation of these terms. Translating political neologisms is rather difficult, as there is often a lack of equivalents in ordinary dictionaries therefore dictionaries covering current language must be updated to reflect new words, and new senses of existing word. Some political neologisms require more than one translation strategy which the translator is not aware of. That is, many of them have to be transferred and explained at the same time. Inability to comprehend the language due to lack of knowledge of the source language or lack of proficiency leads to misunderstanding of the intended meaning of political neologisms. Lack of subject matter knowledge can be a serious problem in the translation process. The translation strategies or techniques which were used and adopted by professional translators in rendering political neologisms are: functional equivalent, cultural equivalent, modulation, compensation, and paraphrase. These strategies were used to convey the most important elements included in English political neologisms into their Arabic equivalents and to provide the readers of the target text with a better understanding.

\section{Recommendations}

The findings of this study indicate a number of recommendations for practice that are useful and needed to be used by translators when translating English political neologisms.

1. Translating English political neologisms should be done by translators who are acquainted and familiar with both the SL and TT culture, because understanding the cultural context helps translators in conveying the right message. Language is an integral part of culture therefore; translating these political neologisms cannot be accurately achieved without considering the culture.

2. Translators are recommended to do some research about the political neologisms they are going to translate before doing their translations. It is important for translators to have the background information relating to subject matter of these political neologisms to help them understand the concepts in order to render the messages properly. When translators understand the background of the original, it provides them with some hints about the meaning and helps them better choose the precise wording to convey the sense that the author intended to convey.

3. Before starting the process of translation translators should read, study and analyze the text comprehensively from a translator point of view, because this is the only way of ensuring that the source text has been completely and correctly understood. "You have 
to study the text not for itself but as something that may have to be reconstituted for a different readership in a different culture" Newmark (1988,p. 18). He also states "there are two approaches to translating (and many compromises between them): (1) you start translating sentence by sentence ...; (2) you read the whole text two or three times. ... You may think the first method more suitable for a literary and the second for a technical or an institutional text. ..." (ibid:19).

4. It is worth mentioning here that achieving a translational equivalent of the political neologisms without considering its contextual use is hard to achieve. Therefore translators must skillfully grasp the overall style of the original text and properly apply translation techniques, in order to achieve the most appropriate equivalence.

5. Extensive reading of various references and having good background knowledge of the subject will compensate for the scarcity of dictionaries and glossaries.

\section{Conclusion}

A translator should be knowledgeable and intelligent enough to grasp the meaning accurately. Moreover, the text type and target readership should be taken into account. The translator has to find out the meaning of political neologisms mainly based on the context in which these terms are used. To translate these terms one should first understand those terms accurately, which is not necessarily an easy job. Being proficient in the source language means understanding the intended meaning of a linguistic utterance, and being proficient in the target language requires the translator to be able to express the intended messages in ways that are equally acceptable to prospective target audiences. The translator has to be well-versed in both source and target cultures to bridge the gap in communication, as cultural meanings are intricately woven into the texture of the language. Translation is therefore not simply a matter of seeking other words with similar meaning but of finding appropriate ways of saying things in another language.

\section{References}

Alnajrani, H., Bajnaid, A., \& Elyas, T. (2018). Exploring the Transitional Era in Saudi Arabia Journalism Discourse and the Path towards the Right to Freedom of Expression. Modern Applied Science, 12(10), 1-12.

Bajnaid, A., Veltri, G., and Elyas, T. (2018). Utilizing Matrimonial Web sites Among Saudi Users: An Empirical Study. Digest of Middle East studies, 1-30.

Beaugrande, Robert de.(2003). On the Concept of Sensitive Translation. Off Shoot,Vol1 .

Bell, R.T.(1991). Translation and Translating: Theory and Practice. London: Longman.

Cabre, T. Terminology: Theory, Methods and Applications.Amsterdam: John Benjamins Publishing Company, 1999. 
Chuquet, Hélène and Michel Paillard.Approchelinguistique des problèmes de la traduction: anglais-français. Paris: Ophrys, 1987. Print.

Crystal, D. (1995) The Cambridge Encyclopedia of the English Language.GB: Cambridge University Press.

Delabastita, D. (2004) 'Literary style in translation: Archaisms and neologisms' in Übersetzung, translation, traduction - Ein internationales Handbuch zur Übersetzungswissenschaft. An International Encyclopedia of Translation Studies. Encyclopédie internationale de la recherché sur la traduction, volume 1. Edited by $\mathrm{H}$. Kittel et al. Berlin \& New York: Walter de Gruyter, 883-888.

Hurtado Albir, Amparo, ed. Enseñar a Traducir.Metodología en la formación de traductores e intérpretes.Teoría y fichasprácticas. Madrid: Edelsa, 1999. Print.

Kelly, D. (2005): A Handbook for Translator Trainers, Translation Practices Explained Series, Manchester, St. Jerome Publishers.

Larose, Robert. Théoriescontemporaines de la traduction. Québec: Presses de I'Université de Québec, 1989. Print.

Leibold, A.1989. The Translation of Humor : Who Says it Can't be Done? Meta, 34(1): 107-111.

Lörscher, Wolfgang. Translation Performance, Translation Process, and Translation Strategies. A Psycholinguistic Investigation.Tübingen: Narr, 1991. Print.

Mattielo, E., (2007). Keeping Lexical Complexity in Slang Translation.

Metcalf, E-M., (2003). „Exploring Cultural Difference through Translating Children"s Literature", Meta, xviii..

Newmark, Peter(1988). A Textbook of Translation.London/New York: Prentice Hall Print. Niska, H.Explorations in translational creativity: Strategies for interpreting neologisms., Stockholm University.

Nolan, J. (2005). Interpretation: Techniques and exercises.Clevedon, $\mathrm{OH}$ : Multilingual Matters.

Parianou, А. \&Kelandrias, Р. П. Special terms: conditions and requirements for their creation and development in the proceedings of the International Conference Translating in the 21stcentury: Trends and Prospects, organized by the Aristoteleio University of Thessaloniki, Faculty of Arts, on 27-29 September, 2002. 
Journal of Social Sciences (COES\&RJ-JSS), 8(1), pp.157-168

Roswitha Fischer. 1998. Lexical Change in Present Day English: A Corpus-Based Study Of the Motivation, Institutionalization, and Productivity of Creative Neologisms. Gunter NarrVerlag, T"ubingen, Germany.Language and culture.

Seguinot, C. (1989). The translation process. Toronto: H.G. Publications.

Silvia, P. (2001)'Handbook of Terminology.' Terminology and standardization Directorate. Translation Bureau.Public Works and Government Services Canada

Vázquez Ayora, Gerardo. Introducción a la traductología. Washington: Georgetown U. Press, 1977. Print.

Venuti, Lawrence. The Scandals of Translation.Towards an ethics of difference. London/New York: Routledge, 1998. Print. 